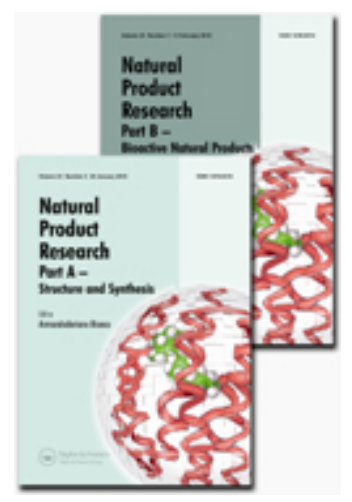

\title{
Scutellaria brevibracteata subsp. subvelutina (Rech.f.) Greuter \& Burdet: morphological and phytochemical characterization
}

\begin{tabular}{|r|l|}
\hline Journal: & Natural Product Research \\
\hline Manuscript ID & GNPL-2020-0307 \\
\hline Manuscript Type: & Research Article \\
\hline Author: & 05-Feb-2020 \\
\hline Complete List of Authors: & $\begin{array}{l}\text { Giuliani, Claudia; Universita degli Studi di Milano, Department of } \\
\text { Pharmaceutical Sciences } \\
\text { Bottoni, Martina; University of Milano, Pharmaceutical Sciences } \\
\text { Ascrizzi, Roberta; Università di Pisa } \\
\text { Santagostini, Laura; University of Milano, Chemistry } \\
\text { Papini, Alessio; University of Florence, Biology } \\
\text { Flamini, Guido; Via Bonanno 33, 56126 Pisa, Italy, Dipartimento di } \\
\text { Farmacia } \\
\text { Fico, Gelsomina; University of Milano, Pharmaceutical Sciences }\end{array}$ \\
\hline Keywords: & $\begin{array}{l}\text { Scutellaria brevibracteata subsp. subvelutina, Micro-morphology, HS- } \\
\text { SPME, Hydrodistillation, GC/MS, VOC profile, Essential oil }\end{array}$ \\
\hline
\end{tabular}

\section{SCHOLARONE" Manuscripts}



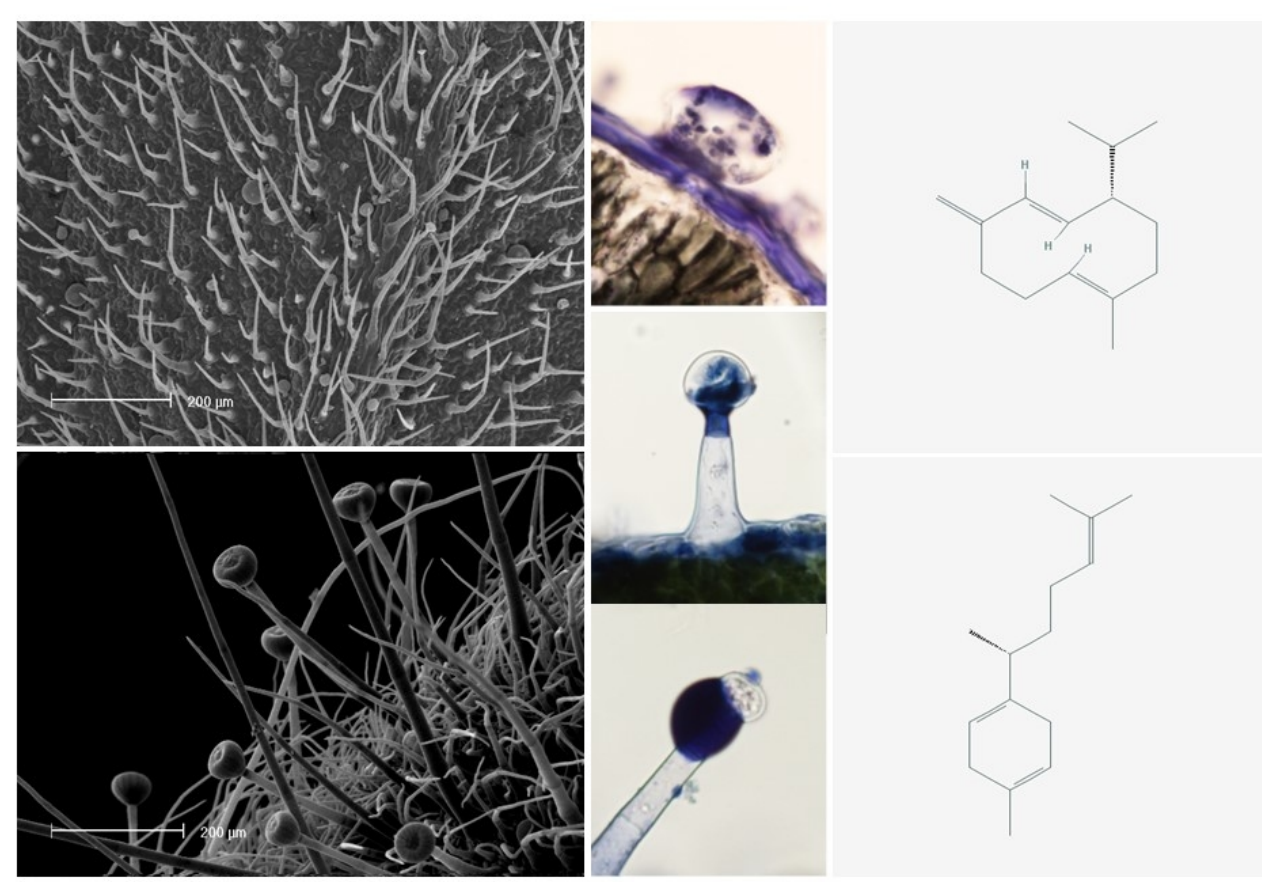

$254 \times 190 \mathrm{~mm}(96 \times 96 \mathrm{DPI})$ 


\section{Scutellaria brevibracteata subsp. subvelutina (Rech.f.) Greuter \& Burdet: morphological and phytochemical characterization.}

Claudia Giuliani ${ }^{a, b},{ }^{* *}$, Martina Bottoni ${ }^{a}, b, * *$, Roberta Ascrizzi $c$, Laura Santagostini d , Alessio Papini e, Guido Flamini c, Gelsomina Fico a,b,*

a Department of Pharmaceutical Sciences, University of Milan, Via Mangiagalli 25, 20133 Milan, Italy; b Ghirardi Botanic Garden, Department of Pharmaceutical Sciences, University of Milan, Via Religione 25, 25088 Toscolano Maderno, Brescia, Italy; ' Department of Pharmacy, University of Pisa, Via Bonanno 6, 56126 Pisa, Italy; d Department of Chemistry, University of Milan, Via Golgi 19, 20133 Milan, Italy; e Department of Biology, University of Florence, Via La Pira 4, 50121 Florence, Italy.

* Corresponding author: gelsomina.fico@unimi.it

** The authors contributed equally to the work. 


\title{
Keywords
}

Scutellaria brevibracteata subsp. subvelutina, Micro-morphology, HS-SPME, Hydrodistillation, GC/MS, VOC profile, Essential oil

\begin{abstract}
A micromorphological and phytochemical survey was performed on Scutellaria brevibracteata subsp. subvelutina (Lamiaceae) cultivated in Italy. The indumentum of the vegetative and reproductive organs was investigated: peltate, short-, medium- and long-stalked capitates were described. Histochemistry evidenced similar results for the peltates and the long-stalked capitates, differences for short and medium capitates. For the first time, this work reported the leaf and flower VOC characterization, together with the first analysis of the EO obtained from the aerial parts of Italian samples. The floral profile resulted more complex than the foliar one, due to the higher number of the total compounds ( 40 vs 27 ) and of the exclusive constituents ( 24 vs 11). 16 common compounds were detected, with $\beta$-caryophyllene as the most abundant one. The EO was characterized by 23 compounds, among which $\beta$-caryophyllene dominated. The peltates, the medium and the long-stalked capitates resulted the producers of the investigated compounds.
\end{abstract}

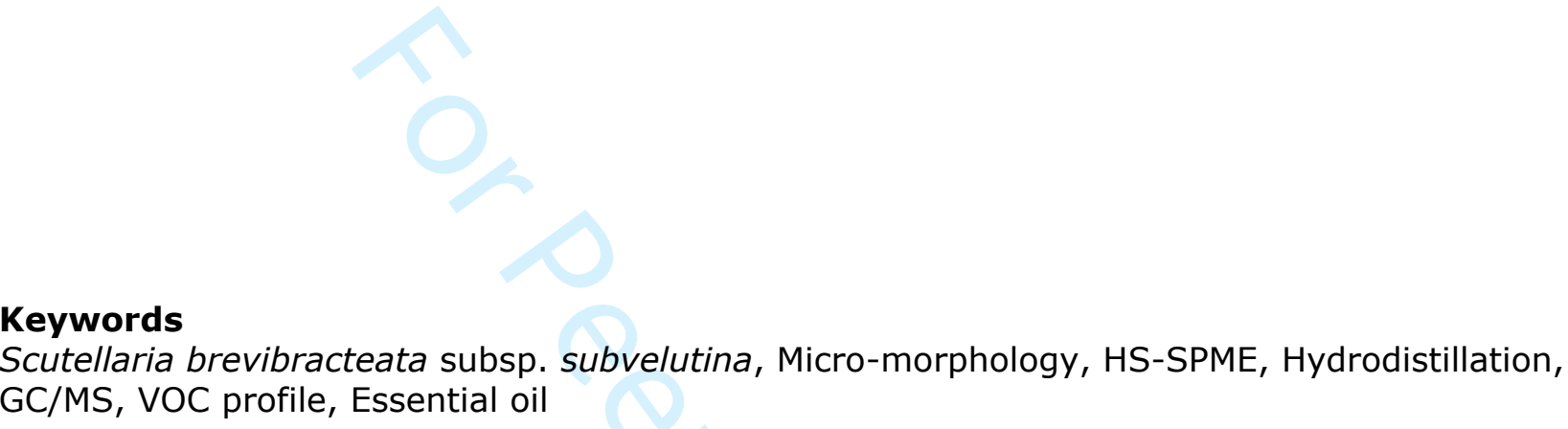




\section{Introduction}

Scutellaria L., commonly known as skullcaps (Formisano et al. 2013; Sripathi and Ravi 2017), is one of the largest genera of the Lamiaceae family and includes 471 species (Yilmaz et al. 2019). The genus has a subcosmopolitan distribution with the main centers of diversity distributed in the Andes, in the Iran-Turanian region and in the Eastern Mediterranean (Paton 1990). In particular, in Turkey, Scutellaria consists of 39 taxa, 17 of which are endemic (Yilmaz et al. 2019).

Scutellaria brevibracteata Stapf. is widespread in the Mediterranean region and includes four subspecies: S. brevibracteata subsp. brevibracteata, S. brevibracteata subsp. icarica (Rech.f.) Greuter \& Burdet, S. brevibracteata subsp. subvelutina (Rech.f.) Greuter \& Burdet and S. brevibracteata subsp. pannosula (Rech.f.) Greuter \& Burdet (Tutin et al. 1972). Among them, the subsp. icarica is located in the Greek islands Ikaria and Samos in the Northern Aegean Sea, nearby the Turkish coasts (Edmondson 1982). The subsp. brevibracteata and subsp. pannosula are endemic of Turkey and subsp. subvelutina is distributed in Southern Turkey and in Western Syria (Yilmaz et al. 2019). The four subspecies differ for the presence of erect or prostrate stems, for the colour and pubescence degree of the leaves, for the corolla length and for the bracts size (Edmondson 1982).

S. brevibracteata subsp. subvelutina is a perennial herb with erect or ascending stems, mostly pubescent at the distal portion and with pubescent leaves, green or violet in colour; the bract length is equal or slightly higher than those of the calyx and the corolla is $14-21 \mathrm{~mm}$ long. A peculiar feature is the presence of velutinose hairs (Edmondson 1982).

Ethnobotanically, little is known about the traditional uses of the species belonging to Scutellaria. In Eastern Anatolia, the infusion of the dried leaves is used for wound healing, as haemostatic and tonic (Özçelik et al. 1990; Baytop 1999). Moreover, its infusion and decoction are considered remedies against tumor and haemorrhoids and show astringent properties (Cakilicioğlu and Türkoğlu 2010). Other uses are described for Scutellaria species from many other places in the world (Kokakowska 2017; Irvin et al. 2019).

In the Lamiaceae family, glandular hairs represent important sites for the synthesis of natural bioactive compounds, which display a crucial role in the seduction towards pollinators or seed dispersers or in the repulsion strategies against phytophagous insects or pests (Maffei 2010; Giuliani et al. 2017).

The literature proposes few morphological studies on the structure of the glandular trichomes in Scutellaria species (Giuliani and Maleci Bini 2008; Dereboylu et al. 2012; De Oliveira et al. 2013; Naghiloo et al. 2014; Cali 2017a; 2017b), none of them referring to S. brevibracteata.

Concerning the phytochemical state of the art, works on the VOC emission profile are lacking, whereas works related to the characterization of the essential oil of Scutellaria species are few (Skaltsa et al. 2000; Yu et al. 2004; Skaltsa et al. 2005; Rosselli et al. 2007). In particular, there are only 2 contributions about S. brevibracteata (Formisano et al. 2013; Yilmaz et al. 2019). The former authors also investigated the ecological role of the essential oil (Formisano et al. 2013).

Regarding the subsp. subvelutina, the literature proposes only one contribution on the analysis of the essential oil composition of plants form Turkey (Yilmaz et al. 2019).

Only one contribution refers about the biological activity of the subspecies, reporting the inhibitory effects on the tyrosinase caused by the methanol extract of the aerial parts (Senol et al. 2010).

This work is part of the project "Botanic Garden, factory of molecules", with the financial support from the Lombardy Region (Italy). In this context, the goals of this work were: $\mathbf{1}$. to describe the morphology and the distribution pattern of the glandular trichomes on the vegetative and reproductive organs of $S$. brevibracteata subsp. subvelutina, by means of light microscopy and scanning electron microscopy; 2. to characterize the secreted substances through histochemical analysis; 3. to correlate the micro-morphological investigation of the secreting structures with the productivity of secondary metabolites through the phytochemical characterization of the volatile organic compounds (VOCs) spontaneously emitted by leaves and flowers and the essential oil (EO) obtained from the aerial parts. 


\section{Results \\ 2.1 Micromorphological investigation}

\subsubsection{Trichome morphotypes and distribution pattern}

The micromorphological survey revealed the occurrence of both glandular and non-glandular trichomes in the indumentum of the investigated organs.

The glandular trichomes belong to two main types, peltate and capitate. The latter may be distinguished into three subtypes: short-, medium-, and long-stalked (Fig. S1, B-D).

The peltate (Fig. S1A) is composed by one basal epidermal cell, one neck cell and 4-8 head cells surrounded by a large storing chamber (30-40 $\mu \mathrm{m}$ in diameter). It is observed on the interveinal regions of the abaxial leaf surface and on the reproductive organs (Fig. S2, B, E, F).

The short-stalked capitate (Fig. S1B, 30-35 $\mu \mathrm{m}$ in length) is made up by one basal cell, one neck cell and 2 secreting cells with a thin subcuticular space $(15-25 \mu \mathrm{m}$ in diameter). It is generally placed in epidermal depressions so that it slightly protrudes from the surface and is ubiquitous to all the investigated organs, with a preferential distribution pattern on the veinal system. The medium-stalked capitate (Fig. S1C, $45-70 \mu \mathrm{m}$ in length) consists of one protruding basal epidermal cell, one stalk cell and of a 2-4-celled head (30-40 $\mu \mathrm{m}$ in diameter). It is sporadically observed on leaves, whereas it is characterized by a higher density on calyces and corollas. The long-stalked capitate (Fig. S1D, $250-400 \mu \mathrm{m}$ in length) is composed by one basal cell, 3-4 stalk cells and by a multicellular head (30-50 $\mu \mathrm{m}$ in diameter) characterized by a small subcuticular space located in the centre. This hair is exclusively observed on the calyx, and it is absent at the skullcap. The distribution pattern of the glandular trichomes is reported in Table S1. The non-glandular hairs are uniseriate with a smooth cuticle and display a different length depending on the organ bearing them (Fig. S2, A-G). Indeed, they are shorter $(70-90 \mu \mathrm{m}$ in length) on leaves, where they appear erect or curved with a sharp tip facing towards the leaf apex (Fig. S2, A-B); they are longer $(150-400 \mu \mathrm{m})$ and thinner on calices and corollas without any preferential orientation.

\subsubsection{Histochemistry}

The results of the histochemical survey on the glandular trichomes are reported in Table $\mathbf{5 2}$ and Fig S3. In the peltate trichomes the responses to all the lipophilic stainings were positive, as well as to $\mathrm{AlCl}_{3}$, indicating the presence of terpenes and of major flavonoid derivatives (Fig. S3, A-C). The secreted material of the short capitate proved positive only to the hydrophilic dyes, indicating the exclusive production of polysaccharides (Fig. S3D). As regards to the medium capitate, the secretion proved positive to all the lipophilic stainings, particularly to the Nadi reagent, indicating that they are exclusive terpene producers (Fig. S3E). The long capitate showed intense positive responses to all the lipophilic dyes, proving the production of terpene derivatives as well as of major polyphenol and flavonoid fractions (Fig. S3, F-H).

\subsection{Phytochemical investigation \\ 2.2.1 VOC emission}

The VOC emission profiles revealed a total of 51 different compounds. 27 and 40 compounds were identified in the leaf and in the flower profiles, respectively (Table 1). In the leaf, the most abundant chemical class was represented by sesquiterpene hydrocarbons $(66.27 \%)$, followed by non-terpene substances $(21.4 \%)$. Oxygenated monoterpenes and hydrocarbons derivatives were present in comparable amounts, $4.82 \%$ and $2.46 \%$, respectively. The main compound was $\beta$-caryophyllene $(28 ; 44.05 \%)$, followed by decanal $(13 ; 10.37 \%), \beta$-bourbonene $(20 ; 5.01 \%)$, $\mathrm{Y}$-muurolene $(38 ; 4.33 \%)$ and nonanal $(8 ; 4.04 \%) .11$ exclusive compounds were identified, among which germacrene D $(39 ; 3.96 \%)$ dominated. The other exclusive compounds occurred in amounts lower than $2.0 \%$. The floral profile was dominated by sesquiterpene hydrocarbons $(88.65 \%)$, followed by non-terpene substances $(4.85 \%)$ and by comparable relative percentages of oxygenated monoterpenes $(1.3 \%)$ and hydrocarbon derivatives $(0.57 \%)$. We also detected oxygenated sesquiterpenes $(2.78 \%)$, totally absent in the leaf profile. The most abundant compound was the sesquiterpene hydrocarbon $\beta$-caryophyllene $(28 ; 26.56 \%)$, followed by $\beta$ curcumene $(45 ; 23.43 \%)$, a-cedrene $(26 ; 8.71 \%), \beta$-bisabolene $(44 ; 6.28 \%)$ and $\gamma$-muurolene (38; $5.72 \%) .24$ exclusive compounds were identified, among which $\beta$-curcumene $(45 ; 23.43 \%)$ was the most abundant one, followed by a-cedrene (26) and $\beta$-bisabolene (44). 
The comparison between the two profiles evidenced the occurrence of 16 common compounds, among which the most abundant was $\beta$-caryophyllene (28), present in different relative abundances: it occurred in leaves (44.05\%) in a percentage value almost double compared to flowers $(26.56 \%)$. Similarly, decanal (13) was more abundant in the leaf profile $(10.37 \%)$, compared to the floral one $(0.2 \%)$. Most of the common compounds, $\beta$-pinene $(2), 1,8$-cineole (5), nonanal (8) and $\beta$-bourbonene (20) occurred in lower amounts in the flowers $(0.33 \%$; $1.03 \% ; 0.11 \% ; 0.16 \%)$, in comparison to the leaves $(2.46 \% ; 3.82 \% ; 4.04 \% ; 5.01 \%)$. aHumulene (35) (2.06\% leaves; $1.94 \%$ flowers) and $\gamma$-muurolene (38) (4.33\% leaves; $5.72 \%$ flowers) were present in comparable percentages, as well as the minor compounds with amounts lower than $1.0 \%$.

\subsubsection{EO profile}

The EO composition is reported in Table 2: a total of 23 compounds were identified, accounting for $96.55 \%$ of the total oil. The extraction yield was $0.06 \%$. Sesquiterpene hydrocarbons represented the most abundant fraction (54.59\%). Oxygenated sesquiterpenes and non-terpene derivatives followed in similar percentage $(14.60 \%$ and $17.45 \%$, respectively), while monoterpenes showed the lower relative abundance. The dominant compound was $\beta$ caryophyllene $(15 ; 42.60 \%)$, followed by hexahydrofarnesylacetone $(23 ; 9.96 \%)$ and linalool $(8 ; 7.80 \%)$. Nonanal $(9 ; 5.57 \%)$, humulene $(16 ; 5.20 \%)$ and caryophyllene oxide $(18 ; 4.82 \%)$ occurred at similar amounts. Except for other three sesquiterpenes $(17 ; 20 ; 22)$, the remaining compounds were present at relative abundances lower than $2.0 \%$.

\section{Discussion}

The glandular trichomes observed on S. brevibracteata subsp. subvelutina corresponded to the two main types widespread in the family Lamiaceae: peltate and capitate (Werker 2000; Giuliani et al. 2017; Najar et al. 2018). The peltates were present both on the vegetative and the reproductive component, as documented in other Scutellaria species (Giuliani and Maleci Bini 2008; Dereboylu et al. 2012; De Oliveira et al. 2013; Cali 2017a; 2017b). In addition, three subtypes of capitates were distinguished: short-, medium- and long-stalked. The capitates were widespread on the whole epidermal surfaces of the plant, with a different distribution pattern for each subtype. The short capitates were ubiquitous, while the medium capitates mostly occurred on calyces and corollas, rarely on the leaves, and the long capitates were exclusively distributed on the calyx. The short-stalked subtypes were described in all Lamiaceae species examined so far (Dereboylu et al. 2012). On the contrary, the medium-stalked capitates had never been observed before in the Scutellaria genus. The long-stalked capitates, with a multicellular head, occurred in S. galericulata (Giuliani and Maleci Bini 2008; Dereboylu et al. 2012;) and in several species of Stachys, representing diagnostic microcharacters for the intra-genus classification. The histochemical analysis revealed a similar complex chemical composition for the peltates and the long-stalked capitates, due to the presence of terpenes and polyphenols, in particular flavonoids. Different secretion profiles were obtained for the short capitates, for the exclusive production of polysaccharides, and for the medium capitates, for the exclusive secretion of terpenes. Although the peltates are considered typical EO producers in the Lamiaceae (Hallahan 2000; Werker 2000), they may display a secretion having a much more complex chemical composition, as it was documented in S. galericulata (Giuliani and Maleci Bini 2008) and in other members of the family. Therefore, our results highlighted that the secretion of terpenes was due to three different trichomes morphotypes: peltates, medium- and long-stalked capitates. However, based on the different distribution pattern, it is possible to hypothesize that this productivity is exclusively due to the peltates on the leaves, while all the trichomes types contribute to the production of these substances on the flowers. Based on the different trichome abundances and on the presence of a broader subcuticular space in the peltates compared to the capitates involved in the same secretion type, it is possible to conclude that peltates represent the main terpenes producers.

Concerning the phytochemical investigation, the analysis of the VOC emission represents an element of novelty. The main chemical class was represented by sesquiterpene hydrocarbons in both profiles, $(66.27 \%$ leaves; $88.65 \%$ flowers), followed by non-terpene derivatives $(21.40 \%$ leaves; $4.85 \%$ flowers), while the oxygenated sesquiterpenes were totally absent in the leaves, similarly to the apocarotenoids in the flowers. Overall, 16 common compounds were identified, dominated by $\beta$-caryophyllene (28), accounting for different percentages: its relative abundance 
was almost double in the leaves $(44.05 \%)$ than in the flowers $(26.56 \%)$. Similarly, decanal (13) was very abundant in the leaves $(10.37 \%)$ compared to the flowers $(0.2 \%)$, while a-humulene (35) $(2.06 \%$ leaves; $1.94 \%$ flowers) and $\gamma$-muurolene (38) (4.33\% leaves; $5.72 \%$ flowers) occurred in similar percentages. However, a high level of variability emerged between the leaf and the flower profiles. Indeed, the floral profile was more complex than the leaves one, because of the presence of a higher number of compounds, 40 and 27 respectively. Moreover, the floral profile was characterized by 24 exclusive compounds, dominated by $\beta$-curcumene $(45 ; 23.43 \%)$, while the leaf profile presented 11 exclusive compounds, among which germacrene $D$ dominated $(39 ; 3.96 \%)$. As regard to the ecological role of the common compounds, previous studies documented that $\beta$-caryophyllene $(28)$ is involved both in the attraction strategies towards pollinators (Zhang 2018), sometimes in association with a-humulene (35) (Abraham et al. 2018), as well as in defence mechanisms against pests, parasites and herbivores (Jürgens et al. 2003; Degenhardt et al. 2009; Dória et al. 2010; Dunkić et al. 2011; Curtois et al. 2012; Smith et al. 2012; Köllner et al. 2013; Feng et al. 2017). This last activity is typical of the sesquiterpene hydrocarbons, especially $\beta$-bourbonene (20) (Birkett et al. 2008), whose biosynthesis may be induced by herbivory (Köllner et al. 2013). Specific studies for the other above-mentioned common compounds are lacking.

Concerning the ecological role of the flower exclusive compounds, $\beta$-curcumene $(45 ; 23.43 \%)$ and a-cedrene $(26 ; 8.71 \%)$ were very abundant:an attracting function towards pollinators is ascribed to them as part of volatile floral phytocomplex (Paulo et al. 2001). All the leaf exclusive compounds were present in relative amounts close to $1 \%$, except for germacrene $D(39)$, to which a defensive role is ascribed (Birkett et al. 2008). (E)-Geranyl acetone (34), a-farnesene (43) and n-tetradecane (24) are involved in different VOC-mediated tritrophic interactions (Pinto-Zevallos et al. 2018; Morawo et al. 2016), while linalool (7) shows both attractive and repulsive actions (Stevenson 2019). On these bases, the protective role should mostly be performed by leaves, also thanks to the higher amount of the common compound with this specific function in comparison to their abundance at flower level. On the contrary, the attractive function is primarily expressed by the flower exclusive bouquet. Nevertheless, because of the presence of double-action compounds in both profiles, especially $\beta$-caryophyllene, a synergy leaf-flower emerges in relation to a protective action.

This work represents the first contribution about the EO characterization of the S. brevibracteata subsp. subvelutina from Italy. The obtained oil yield was very low $(0.06 \%)$, as documented for other congeneric species (Rosselli et al. 2007; Formisano et al. 2013). From a quantitative point of view, the Italian subspecies EO showed a lower number of total compounds, 23, compared to the same subspecies from Turkey, 44 (Yilmaz et al. 2019). Nevertheless, in both cases, sesquiterpene hydrocarbons were the main compound class and the most abundant compound was $\beta$-caryophyllene, as resulted in the Turkish subspecies (Yilmaz et al. 2019). Concerning the other compounds, several differences emerged: in the plants from Turkey, linalool $(12.4 \%)$ and hexadecanoic acid (10.8\%) occurred in considerable amounts, whereas, for the Italian subspecies, only linalool $(7.8 \%)$ was present, associated with hexahydrofarnesylacetone $(9.96 \%)$, accounting for $2.3 \%$ in the Turkish sample. In their work referred to the species $S$. brevibracteata, Formisano et al. (2013) reported that the EO of samples from Lebanon was dominated by $\beta$-caryophyllene (14.4\%), followed by hexadecanoic acid $(12.6 \%)$, phytol $(10.7 \%)$ and 4-vinylguaiacol (10.2\%). In addition, germacrene $D$ was one of the main compounds in most of the EO of congeneric species (Cicek et al. 2010; Cicek et al. 2011) whereas, in our samples, this molecule is present in lower amount (3.88\%). However, the comparison with literature data resulted problematic due to the different geographical origin of the samples and to the fact that the subspecies taxonomic level is not indicated by Formisano et al. (2013).

Concerning the EO biological activity, antifeedant properties towards Spodoptera littoralis, a serious crop pest, was reported (Formisano et al. 2013; Ribeiro et al. 2015;), as well as an action in the modulation of the insect feeding behaviour (Formisano et al. 2013).

This work represents a further step in the characterization of the species collected at the G. E. Ghirardi Botanic Garden (Toscolano Maderno, Lombardy, Italy), which is totally dedicated to medicinal plants. This multidisciplinary approach will help to present scientific insight on the species to the visitors and convey a new awareness of the plant organism. 


\section{Acknowledgments}

The authors are grateful to the Lombardy Region for the financial support of the project "Botanic Garden, factory of molecules", under the Call for the Enhancement of Museum Ir. 25/2016, year 2019.

\section{Conflicts of interest}

The authors declare no conflicts of interest.

\section{References}

Abraham AA, Verghese A, Muthangi S. 2018. Role of colour and volatile in foraging behaviour of honeybee Apis cerana on Jacquemontia pentanthos. J Asia-Pac Entomol. 21(4):1122-1128.

Baytop T. 1999. Therapy with medicinal plants in Turkey, past and present. 2nd edn., Nobel Tip Kitabevleri. Istanbul:375.

Beccari N, Mazzi V. 1966. Manual of microscopic technique. Como: Società Editrice Libraria.

Birkett MA, Al Abassi S, Kröber T, Chamberlain K, Hooper AM, Guerin PM, Pettersson J, Pickett AJ, Slade R, Wadhams LJ. 2008. Antiectoparasitic activity of the gum resin, gum haggar, from the East African plant, Commiphora holtziana. Phytochemistry. 69(8):1710-1715.

Brundrett MC, Kendrick B, Peterson CA. 1991. Efficient lipid staining in plant material with Sudan Red 7B or Fluoral Yellow 088 in polyethylene glycol-glycerol. Biotech Histochem. 66:111-116.

Cakilicioğlu U, Türkoğlu I. 2010. An ethnobotanical survey of medicinal plants in Sivrice (Elaziğ-Turkey). J. Ethnopharmacol. 132:165-175.

Çalı İÖ. 2017a. Anatomical and glandular trichome characteristics of Scutellaria salviifolıa (Lamiaceae) endemic to Turkey. Int J Agric Biol. 19(4):654-658.

Cali IO. 2017b. Anatomy and glandular trichome micromorphology of Scutellaria orientalis L. subsp. pinnatifida Edmondtson (Lamiaceae).

Cicek M, Demirci B, Yilmaz G, Ketenoglu O, Baser KHC. 2010. Composition of the essential oils of subspecies of Scutellaria albida L. from Turkey. J Essent Oil Res. 22(1):55-58.

Cicek M, Demirci B, Yilmaz G, Baser KHC. 2011. Essential oil composition of three species of Scutellaria from Turkey. Nat prod res. 25(18):1720-1726.

Courtois EA, Baraloto C, Paine CT, Petronelli P, Blandinieres PA, Stien D, Höuel E, Bessière JM, Chave J. 2012. Differences in volatile terpene composition between the bark and leaves of tropical tree species. Phytochemistry. 82:81-88.

David R, Carde JP. 1964. Coloration differentielle des inclusions lipidiques et terpeniques des pseudophylles du Pin maritime au moyen du reactif NADI. C R Acad Sci Paris. 258:1338-1340.

Degenhardt J, Hiltpold I, Köllner TG, Frey M, Gierl A, Gershenzon J, Hibbard BE, Ellersieck MR., Turlings TC. 2009. Restoring a maize root signal that attracts insect-killing nematodes to control a major pest. Proc Natl Acad Sci. 106(32):13213-13218.

De Oliveira AB, De Mendonça MS, Meira RM. 2013. Anatomy of vegetative organs of Scutellaria agrestis, a medicinal plant cultivated by riverine populations of the Brazilian Amazon. Rev Bras Farmacogn. 23(3):386-397.

Dereboylu AE, Sarikahya NB, Sengonca N, Kirmizigul S, Yasa I, Gucel S, Guvensen A. 2012. Glandular trichomes morphology, chemical composition and antimicrobial activity of the essential oil of three endemic Scutellaria taxa (Lamiaceae). Asian J. Chem. 24(11):4911-4916.

Dória GA, Silva WJ, Carvalho GA, Alves PB, Cavalcanti SC. 2010. A study of the larvicidal activity of two Croton species from northeastern Brazil against Aedes aegypti. Pharm biol. 48(6):615-620.

Dunkić V, Bezić N, Vuko E. 2011. Antiphytoviral activity of essential oil from endemic species Teucrium arduini. Nat Prod Commun. 6(9): 1934578X1100600940.

Edmondson JR. 1982. Scutellaria L. In: Davis PH. (Ed.) Flora of Turkey and the East Aegean Islands. Vol. 7. Edinburgh University Press. Edinburgh:78-100.

Feng B, Qian K, Du YJ. 2017. Floral volatiles from vigna unguiculata are olfactory and gustatory stimulants for oviposition by the bean pod borer moth Maruca vitrata. Insects. 8(2):60.

Formisano C, Rigano D, Senatore F, Arnold NA, Simmonds MSJ, Rosselli S, Bruno M, Loziene K. 2013. Essential oils of three species of Scutellaria and their influence on Spodoptera littoralis. Biochem. Syst. Ecol. 48:206-210.

Gahan PB. 1984. Plant Histochemistry and Cytochemistry: An Introduction. London: Academic Press.

Giuliani C, Bini LM. 2008. Insight into the structure and chemistry of glandular trichomes of Labiatae, with emphasis on subfamily Lamioideae. Plant Syst. Evol. 276(3-4):199.

Giuliani C, Ascrizzi R, Tani C, Bottoni M, Maleci Bini L, Flamini G, Fico G. 2017. Salvia uliginosa Benth: glandular trichomes as bio-factories of volatiles and essential oil. Flora. 233:12-21.

Greenspan P, Mayer EP, Fowler SD. 1985. Nile red: a selective fluorescent stain for intracellular lipids droplets. J Cell Biol. 100:965-973.

Guerin HP, Delaveau PG, Paris RR. 1971. Localisations histochimiques.: II: Procedes simples de localisation de pigments flavoniques. Application a quelques Phanerogames. Bull Soc Bot France. 118:29-36. 
Hallahan DL. 2000. Monoterpenoid biosynthesis in glandular trichomes ofLabiatae plants. In: Hallahan, D.L., Gray, J.C. (Eds.). Advances in Botanical Research. Plant Trichomes. Academic Press, New York, London:77-120.

Irvin L, Jackson C, Hill AL, Bajaj R, Mahmoudi C, Brajesh NV, Joshee N (2019) Skullcaps (Scutellaria spp.): Ethnobotany and Current Research. In: Joshee N., Dhekney S., Parajuli P. (eds) Medicinal Plants. Springer, Cham. 141-168 pp.

Jensen WA. 1962. Botanical histochemistry: principles and practice. San Francisco: WH Freeman \& Co.

Jürgens A, Witt T, Gottsberger G. 2003. Flower scent composition in Dianthus and Saponaria species (Caryophyllaceae) and its relevance for pollination biology and taxonomy. Biochem Syst Ecol. 31(4):345-357.

Köllner TG, Lenk C, Schnee C, Köpke S, Lindemann P, Gershenzon J, Degenhardt J. 2013. Localization of sesquiterpene formation and emission in maize leaves after herbivore damage. BMC Plant Biol. 13:15.

Kosakowska O (2017) Intrapopulation variability of flavonoid content in roots of Baikal skullcap (Scutellaria baicalensis Georgi). Herba Pol 63(1):20-31.

Morawo T, Burrows M, Fadamiro H. 2016. Electroantennogram response of the parasitoid, Microplitis croceipes to host-related odors: The discrepancy between relative abundance and level of antennal responses to volatile compound. F1000Research. 5.

Naghiloo S, Gohari GR, Nikzat Siahkolaee S, Dadpour MR. 2015. Floral development in Scutellaria pinnatifida (Lamiaceae): the ontogenetic basis for sepal reduction. Plant Biol. 17(1):238-244.

Najar B, Pistelli L, Cervelli C, Fico G, Giuliani C. 2018. Salvia broussonetii Benth.: aroma profile and micromorphological analysis. Nat Prod Res. 32(14):1660-1668.

Özçelik H, Ay G, Öztürk M. 1990. Some traditional plants of East and Southern Anatolia. Proceedings of the 10th National Symposium on Biology, Atatürk University, Erzurum:1-10.

Paton A. 1990. The phytogeography of Scutellaria L. Notes from the Royal Botanic Garden. Edinburgh. 46(3):345-359.

Paulo CDL, Bittrich V, Shepherd GJ, Lopes AV, Marsaioli AJ. 2001. The ecological and taxonomic importance of flower volatiles of Clusia species (Guttiferae). Phytochemistry. 56(5):443-452.

Pinto-Zevallos DM, Bezerra RH, Souza SR, Ambrogi BG. 2018. Species-and density-dependent induction of volatile organic compounds by three mite species in cassava and their role in the attraction of a natural enemy. Exp Appl Acarol. 74(3):261-274.

Ribeiro RC, Zanuncio TV, De Sousa Ramalho F, Da Silva CAD, Serrão JE, Zanuncio JC. 2015. Feeding and oviposition of Anticarsia gemmatalis (Lepidoptera: Noctuidae) with sublethal concentrations of ten condiments essential oils. Ind Crops Prod. 74:139-143.

Richardson IBK. 1972. Scutellaria L.Tutin, T. G., Heywood, V. H., Burges, N. A., Moore, D. M., Valentine, D. H., Walters, S. M., Webb, D. A. (Eds). In: Flora Europaea. Vol. 3, Cambridge University Press, Cambridge: $135-136$.

Rosselli S, Bruno M, Simmonds MSJ, Senatore F, Rigano D, Formisano C. 2007. Volatile constituents of Scutellaria rubicunda Hornem subsp. linnaeana (Caruel) Rech. (Lamiaceae) endemic in Sicily. Biochem. Syst. Ecol. 35:797-800.

Şenol FS, Orhan I, Yilmaz G, Cicek M, Şener B. 2010. Acetylcholinesterase, butyrylcholinesterase, and tyrosinase inhibition studies and antioxidant activities of 33 Scutellaria L. taxa from Turkey. Food Chem. Toxicol. 48(3): 781-788.

Shang X, He X, He X, Li M, Zhang R, Fan P, Zhang Q, Jia Z. 2010. The genus Scutellaria an ethnopharmacological and phytochemical review. J. Ethnopharmacol. 128:279-313.

Skaltsa HD, Lazari DM, Mavromati AS, Tiligada EA, Constantinidis TA. 2000. Composition and antimicrobial activity of the essential oil of Scutellaria albida ssp. albida from Greece. Planta Med. 66 (7):672-674.

Skaltsa HD, Lazari DM, Kyriazopoulos P, Golegou S, Triantaphyllidis S, Sokovic M, Kypriotakis Z. 2005. Composition and antimicrobial activity of the essential oils of Scutellaria sieberia Benth. and Scutellaria rupestris Boiss. et Heldr. ssp. adenotricha (Boiss. et. Heldr.) Greuter et Burdet from Greece. J. Essent. Oil Res. 17(2):232-235.

Smith WEC, Shivaji R, Williams WP, Luthe DS, Sandoya GV, Smith CL, Sparks DL, Brown AE. 2012. A maize line resistant to herbivory constitutively releases (E)- $\beta$-caryophyllene. J econ entomol. 105(1):120-128.

Sripathi R, Ravi S. 2017. Ethnopharmacology, phytoconstituents, essential oil composition and biological activities of the genus Scutellaria. J. Pharm. Sci. \& Res. 9(3):275-287.

Stevenson PC. 2019. For antagonists and mutualists: the paradox of insect toxic secondary metabolites in nectar and pollen. Phytochem Rev:1-12.

Werker E. 2000. Trichome diversity and development. In: Hallahan, D.L., Gray, J.C.(Eds.), Advances in Botanical Research. Plant Trichomes. Academic Press. NewYork London:1-35.

Yilmaz G, Ciçek M, Demirci B, Başer HC. 2019. Essential oil compositions of subspecies of Scutellaria brevibracteata Stapf from Turkey. J. Essent. Oil. Res. 31(4):255-262.

Yu J, Lei J, Yu H, Cai X, Zou G. 2004. Chemical composition and antimicrobial activity of the essential oil of Scutellaria barbata. Phytochemistry. 65(7):881-884.

Zhang XM. 2018. Floral volatile sesquiterpenes of Elsholtzia rugulosa (Lamiaceae) selectively attract Asian honeybees. J Appl Entomol. 142(3):359-362. 
Table 1. HS-SPME profiles of the leaves and flowers of Scutellaria brevibracteata subsp. subvelutina

\begin{tabular}{|c|c|c|c|c|}
\hline & \multirow{2}{*}{ I.r.i. } & \multirow{2}{*}{ Compounds } & \multicolumn{2}{|c|}{ Relative Abundance (\%) } \\
\hline & & & Leaves & Flowers \\
\hline 1 & 941 & a-pinene & - & $\operatorname{tr}$ \\
\hline 2 & 982 & $\beta$-pinene & 2,46 & 0.33 \\
\hline 3 & 1009 & (Z)-3-hexenol acetate & - & 0.21 \\
\hline 4 & 1032 & limonene & $\operatorname{tr}$ & 0.12 \\
\hline 5 & 1034 & 1,8-cineole (=eucalyptol) & 3.82 & 1.03 \\
\hline 6 & 1062 & Y-terpinene & - & 0.12 \\
\hline 7 & 1101 & linalool & $\operatorname{tr}$ & - \\
\hline 8 & 1102 & nonanal & 4.04 & 0.11 \\
\hline 9 & 1143 & camphor & 1.00 & 0.27 \\
\hline 10 & 1172 & 1-nonanol & 0.77 & - \\
\hline 11 & 1189 & a-terpineol & - & $\operatorname{tr}$ \\
\hline 12 & 1192 & methyl salicylate & $\mathrm{tr}$ & 0.17 \\
\hline 13 & 1204 & decanal & 10.37 & 0.20 \\
\hline 14 & 1227 & methyl nonanoate & - & $\operatorname{tr}$ \\
\hline 15 & 1306 & undecanal & 1.24 & - \\
\hline 16 & 1328 & methyl decanoate & - & 3.94 \\
\hline 17 & 1345 & 7-epi-silphiperfol-5-ene & - & 0.46 \\
\hline 18 & 1351 & a-cubebene & 1.33 & 1.01 \\
\hline 19 & 1376 & a-copaene & 1.76 & 0.49 \\
\hline 20 & 1384 & $\beta$-bourbonene & 5.01 & 0.16 \\
\hline 21 & 1388 & a-duprezianene & - & 1.89 \\
\hline 22 & 1390 & $\beta$-cubebene & 0.44 & 1.56 \\
\hline 23 & 1398 & 1,7-di-epi-a-cedrene & - & 0.28 \\
\hline 24 & 1399 & $n$-tetradecane & 1.02 & - \\
\hline 25 & 1402 & italicene & - & 0.72 \\
\hline 26 & 1409 & a-cedrene & - & 8.71 \\
\hline 27 & 1418 & $\beta$-cedrene & - & $\operatorname{tr}$ \\
\hline 28 & 1420 & $\beta$-caryophyllene & 44.05 & 26.56 \\
\hline 29 & 1429 & $\beta$-copaene & 0.73 & 0.58 \\
\hline 30 & 1430 & methyl undecanoate & - & 0.22 \\
\hline 31 & 1432 & $\beta$-gurjunene & 1.16 & - \\
\hline 32 & 1441 & aromadendrene & $\operatorname{tr}$ & $\operatorname{tr}$ \\
\hline 33 & 1447 & cis-muurola-3,5-diene & - & 0.23 \\
\hline 34 & 1453 & (E)-geranyl acetone & 1.30 & - \\
\hline 35 & 1456 & a-humulene & 2.06 & 1.94 \\
\hline 36 & 1460 & $(E)$ - $\beta$-farnesene & - & 1.29 \\
\hline 37 & 1463 & a-acoradiene & - & 0.79 \\
\hline 38 & 1477 & $Y$-muurolene & 4.33 & 5.72 \\
\hline 39 & 1482 & germacrene D & 3.96 & - \\
\hline 40 & 1483 & ar-curcumene & - & 2.77 \\
\hline 41 & 1495 & a-zingiberene & - & 3.64 \\
\hline 42 & 1500 & $n$-pentadecane & 1.22 & - \\
\hline 43 & 1507 & $(E, E)$-a-farnesene & 1.44 & - \\
\hline 44 & 1509 & $\beta$-bisabolene & - & 6.28 \\
\hline 45 & 1512 & $\beta$-curcumene & - & 23.43 \\
\hline 46 & 1524 & $\delta$-cadinene & - & 0.14 \\
\hline 47 & 1549 & elemol & - & 1.92 \\
\hline 48 & 1581 & caryophyllene oxide & - & 0.11 \\
\hline 49 & 1600 & $n$-hexadecane & 1.95 & - \\
\hline 50 & 1603 & 5,7-di-epi-a-eudesmol & - & 0.75 \\
\hline 51 & 1700 & $n$-heptadecane & 0.79 & - \\
\hline & & Monoterpene hydrocarbons & 2.46 & 0.57 \\
\hline & & Oxygenated monoterpenes & 4.82 & 1.30 \\
\hline & & Sesquiterpene hydrocarbons & 66.27 & 88.65 \\
\hline & & Oxygenated sesquiterpenes & - & 2.78 \\
\hline & & Apocarotenoids & 1.30 & - \\
\hline & & Non-terpene derivatives & 21.4 & 4.85 \\
\hline & & Total & $96.25 \%$ & $98.15 \%$ \\
\hline
\end{tabular}


Table 2. Composition of the essential oil obtained from the aerial parts of Scutellaria brevibracteata subsp. subvelutina

\begin{tabular}{|c|c|c|c|}
\hline & I.r.i. & Compounds & $\begin{array}{c}\text { Relative } \\
\text { Abundance \% }\end{array}$ \\
\hline 1 & 998 & octanal & 0.38 \\
\hline 2 & 1011 & $\delta$-2-carene & 0.09 \\
\hline 3 & 1026 & limonene & 0.17 \\
\hline 4 & 1031 & $(E)$ - $\beta$-ocimene & 0.13 \\
\hline 5 & 1043 & trans-a-ocimene & 0.28 \\
\hline 6 & 1055 & $\mathrm{Y}$-terpinene & 0.16 \\
\hline 7 & 1060 & (E)-2-octenal & 0.40 \\
\hline 8 & 1094 & linalool & 7.80 \\
\hline 9 & 1098 & nonanal & 5.57 \\
\hline 10 & 1193 & terpineol & 1.29 \\
\hline 11 & 1261 & (Z)-2-decenal & 1.15 \\
\hline 12 & 1339 & $\beta$-longipinene & 0.84 \\
\hline 13 & 1369 & a-copaene & 0.68 \\
\hline 14 & 1377 & $\beta$-bourbonene & 1.38 \\
\hline 15 & 1415 & $\beta$-caryophillene & 42.60 \\
\hline 16 & 1451 & a-humulene & 5.20 \\
\hline 17 & 1477 & germacrene D & 3.88 \\
\hline 18 & 1581 & caryophyllene oxide & 4.82 \\
\hline 19 & 1622 & humulene oxide II & 1.58 \\
\hline 20 & 1635 & trans-a-bisabolene epoxide & 3.42 \\
\hline 21 & 1659 & $\beta$-acaredienol & 1.23 \\
\hline 22 & 1686 & a-bisabolol & 3.54 \\
\hline \multirow[t]{10}{*}{23} & 1834 & hexahydrofarnesyl acetone & 9.96 \\
\hline & & (2) & \\
\hline & & Monoterpene hydrocarbons & 0.83 \\
\hline & & Oxygenated monoterpenes & 9.09 \\
\hline & & Sesquiterpene hydrocarbons & 54.59 \\
\hline & & Oxygenated sesquiterpenes & 14.60 \\
\hline & & Apocarotenoids & 9.96 \\
\hline & & Non-terpene derivatives & 7.49 \\
\hline & & 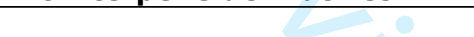 & \\
\hline & & Total & 96.55 \\
\hline
\end{tabular}




\section{Scutellaria brevibracteata subsp. subvelutina (Rech.f.) Greuter \& Burdet: morphological and phytochemical characterization.}

Claudia Giuliani a,b,**, Martina Bottoni a,b, ${ }^{* *}$, Roberta Ascrizzi c , Laura Santagostini d , Alessio Papini e, Guido Flamini c, Gelsomina Fico a,b,*

a Department of Pharmaceutical Sciences, University of Milan, Via Mangiagalli 25, 20133 Milan, Italy; b Ghirardi Botanic Garden, Department of Pharmaceutical Sciences, University of Milan, Via Religione 25, 25088 Toscolano Maderno, Brescia, Italy; ' Department of Pharmacy, University of Pisa, Via Bonanno 6, 56126 Pisa, Italy; d Department of Chemistry, University of Milan, Via Golgi 19, 20133 Milan, Italy; e Department of Biology, University of Florence, Via La Pira 4, 50121 Florence, Italy.

* Corresponding author: gelsomina.fico@unimi.it

** The authors contributed equally to the work.

\section{Materials and methods}

\section{$1.1 \quad$ Plant material}

Scutellaria brevibracteata subsp. subvelutina is cultivated at the Ghirardi Botanic Garden (Toscolano Maderno, BS, Italy) of the Department of Pharmaceutical Sciences of the University of Milan. The sampling for the micro-morphological analysis was carried out on plants in fullbloom in summer 2019. Collection of plant material for the phytochemical investigation (VOCs and essential oil) was performed simultaneously.

\subsection{Micromorphological analysis}

The indumentum was examined on both the vegetative and the reproductive organs (leaves, calyces and corollas) by means of light microscopy, as well as scanning electron microscopy. At least ten replicates of each plant part were collected and examined to assess the micromorphological variability of the indumentum.

\subsubsection{Light microscopy (LM)}

Histochemical investigation was performed to evidence the main chemical classes of metabolites in the trichome secretory products. For each replicate of all the fresh plant parts, hand-made sections (40-50 $\mu \mathrm{m}$ thick) and semi-thin sections (20-25 $\mu \mathrm{m}$ thick) obtained by means of a cryostat, were stained with the following dyes: Fluoral Yellow-088 for total lipids (Brundrett et al. 1991), Nile Red for neutral lipids (Greenspan et al. 1985), Nadi reagent for terpenes (David and Carde 1964), Ruthenium Red for acid polysaccharides (Jensen 1962), Alcian Blue for mucopolysaccharides (Beccari and Mazzi 1966), Ferric Trichloride for polyphenols (Gahan 1984) and alluminium trichloride for flavonoids (Guerin et al. 1971). Control procedures were also performed for all the histochemical dyes. Primary fluorescence of the trichome secretory products were also evaluated under UV and Blue lights. Observations were performed under a Leitz DM-RB Fluo Optic microscope equipped with a digital camera Nikon DS-L1.

\subsubsection{Scanning electron microscopy (SEM)}

For each of the investigated plant parts, small segments were fixed in FAA (formaldehyde: glacial acetic acid: $70 \%$ ethanol 5:5:90 by volume) at $4^{\circ} \mathrm{C}$ for 7 days. Therefore, the samples were dehydrated in ascending ethanol series up to absolute with 20-min intervals, transferred to acetone, critical point-dried in a Balzer Union CPD 020 apparatus and sputter coated with gold. Observations were made under a Philips scanning electron microscope at an accelerating voltage of $20 \mathrm{Kv}$.

\subsection{Phytochemical investigation}


GC/MS Analysis - The analyses of the headspace compositions were performed at the Department of Pharmacy of the University of Pisa. The GC/EI-MS analyses were performed with a Varian CP-3800 apparatus equipped with a DB-5 capillary column (30 m X $0.25 \mathrm{~mm}$ i.d., film thickness $0.25 \mu \mathrm{m}$ ) and a Varian Saturn 2000 ion-trap mass detector. The oven temperature was programmed rising from $60^{\circ} \mathrm{C}$ to $240^{\circ} \mathrm{C}$ at $3^{\circ} \mathrm{C} / \mathrm{min}$; injector temperature, $220^{\circ} \mathrm{C}$; transfer-line temperature, $240^{\circ} \mathrm{C}$; carrier gas, $\mathrm{He}(1 \mathrm{~mL} / \mathrm{min})$. The acquisition parameters were as follows: full scan; scan range: $35-300 \mathrm{~m} / \mathrm{z}$; scan time: $1.0 \mathrm{sec}$; threshold: 1 count.

The identification of the constituents was based on the comparison of their retention times $\left(t_{R}\right)$ with those of pure reference samples and their linear retention indices (LRIs) determined relatively to the $t_{R}$ of a series of $n$-alkanes. The mass spectra were compared with those listed in the commercial libraries NIST 14 and ADAMS and in a home-made mass-spectral library, built up from pure substances and commercial essential oils of known composition, and MS literature data (Adams, 1995).

\subsubsection{EO}

Plant aerial parts at blooming were dried at room temperature in the dark and stored under the same conditions until the hydrodistillation process. The EO hydrodistillation was performed in a standard Clevenger apparatus for $2 \mathrm{~h}$.

$O E$ - EO was obtained by hydrodistillation with a Clevenger apparatus.

GC/MS Analysis - GC-MS analyses were performed at the Department of Chemistry, University of Milan, using a TRACE ISQ QD Single Quadrupole GC-MS.

EO separation was performed by a capillary column VF-5ms ( $5 \%$ phenyl-methyl-polisiloxane, length $30 \mathrm{~m}, 0,25 \mathrm{~mm}$ i.d., $0.1 \mu \mathrm{m}$ film thickness); the temperature gradient was: $8 \mathrm{~min}$ at 50 ${ }^{\circ} \mathrm{C}$, then $4^{\circ} \mathrm{C} / \mathrm{min}$ till $60^{\circ} \mathrm{C}$, then $6^{\circ} \mathrm{C} / \mathrm{min}$ from $60^{\circ} \mathrm{C}$ to $160^{\circ} \mathrm{C}$ and finally $20^{\circ} \mathrm{C} / \mathrm{min}$ from $160{ }^{\circ} \mathrm{C}$ to $280{ }^{\circ} \mathrm{C}$. Injector and detector temperatures were set to $280^{\circ} \mathrm{C}$; carrier gas $\mathrm{He}$, flux 1 $\mathrm{ml} / \mathrm{min}$ : the mass range detected was $50-500 \mathrm{~m} / \mathrm{z}$. EO were analyzed pure or diluted 1:100 with $\mathrm{n}$-hexane, with injection volume of $1 \mu \mathrm{l}$.

Mass spectra were analyzed by Wiley Mass spectra Library, NIST Mass Spectral Search Program e NIST Tandem Mass Spectral library 2.3; compounds were identified by mass fragmentation and retention index, compared with data stored in mass databases (WILEY, NIST18). 
Tables

Table S1. Distribution pattern of the glandular trichomes.

\begin{tabular}{|c|c|c|c|c|c|c|}
\hline Trichome type & $\begin{array}{c}\text { Leaf abaxial } \\
\text { surface }\end{array}$ & $\begin{array}{c}\text { Leaf adaxial } \\
\text { surface }\end{array}$ & $\begin{array}{c}\text { Calyx } \\
\text { abaxial } \\
\text { surface }\end{array}$ & $\begin{array}{c}\text { Calyx } \\
\text { adaxial } \\
\text { surface }\end{array}$ & $\begin{array}{c}\text { Corolla } \\
\text { abaxial } \\
\text { surface }\end{array}$ & $\begin{array}{c}\text { Corolla } \\
\text { adaxial } \\
\text { surface }\end{array}$ \\
\hline Peltate & ++ & - & - & ++ & - & ++ \\
\hline Short-capitate & ++ & ++ & - & + & - & + \\
\hline Medium-capitate & + & - & - & + & - & + \\
\hline Long-capitate & - & - & - & ++ & - & - \\
\hline
\end{tabular}

$(-)$ absent; (+) present; (++) abundant

Table S2. Results of the histochemical tests on the glandular trichomes.

\begin{tabular}{|l|l|c|c|c|c|}
\hline Stainings & Target-compounds & peltate & $\begin{array}{c}\text { short } \\
\text { capitate }\end{array}$ & $\begin{array}{c}\text { medium } \\
\text { capitate }\end{array}$ & $\begin{array}{c}\text { long } \\
\text { capitate }\end{array}$ \\
\hline Fluoral yellow-088 & Total lipids & ++ & - & ++ & ++ \\
\hline Nile Red & Neutral lipids & + & - & + & + \\
\hline Nadi reagent & Terpenoids & ++ & - & ++ & ++ \\
\hline Ruthenium Red & Acid polysaccharides & - & + & - & - \\
\hline Alcian Blue & Mucopolysaccharides & - & + & - & - \\
\hline Ferric Tricholoride & Polyphenols & + & - & - & + \\
\hline Aluminium Trichloride & Flavonoids & + & - & - & + \\
\hline
\end{tabular}

$(-)$ negative; $(+)$ positive; $(++)$ strongly positive 
Figure S1 a-f. Glandular trichome morphotypes in S. brevibracteata subsp. subvelutina. LM. A. Peltate. B. short-stalked capitate. C. Medium-stalked capitate. D. Long-stalked capitate.

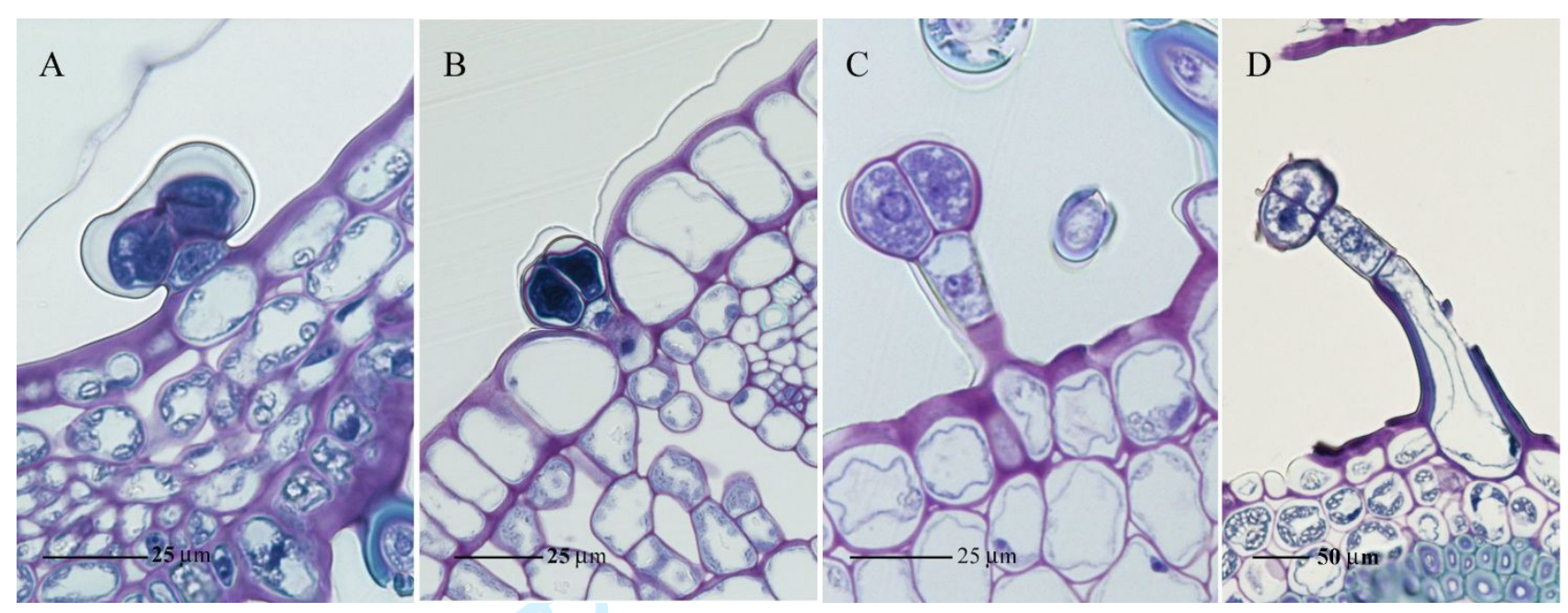


Figure S2. Trichomes distribution pattern in S. brevibracteata subsp. subvelutina. SEM. A. Leaf adaxial surface with peltates, short and medium capitates and non-glandular trichomes. B. Leaf abaxial surface with short and medium capitate and non-glandular hairs. C. General view of a flower with evident abundant non-glandular hairs and long capitates. D. Calyx abaxial surface below the skullcup with long capitates. E. Calyx abaxial side above the skullcup with medium and long capitates. F. Corolla abaxial surface with peltates and short capitates. G, H. Long capitate trichomes; note the particular of the secreting head. 

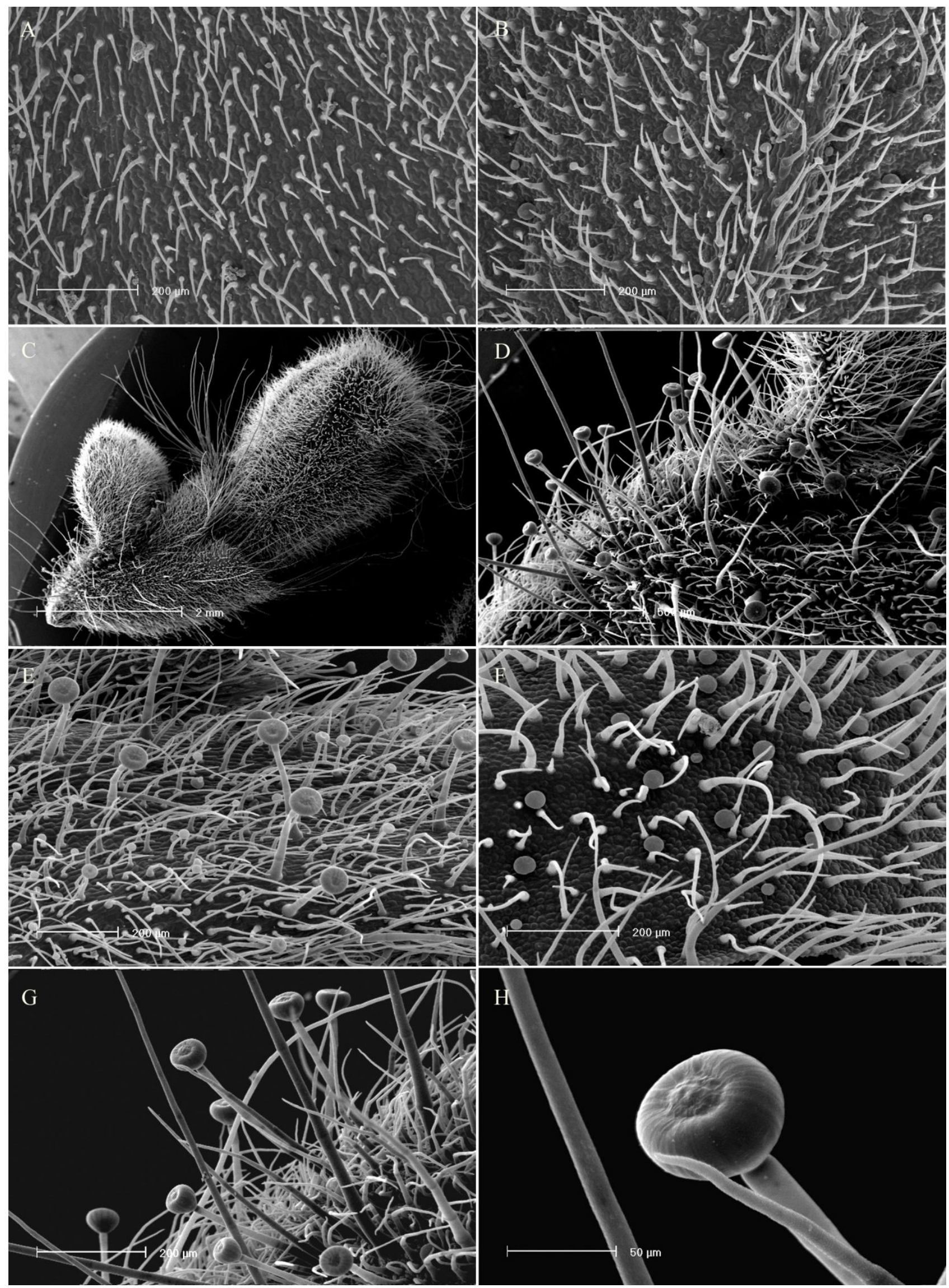
Figure S3. Histochemistry of the glandular trichomes $S$. brevibracteata subsp. subvelutina, LM. A-C. Peltate trichome: Nadi reagent (A); $\mathrm{FeCl} 3$ (B); $\mathrm{AlCl} 3$ (C). D. Short capitate trichome: Alcian Blue. E. Medium capitate trichome: Nadi reagent. F-H. Long capitate trichome: Fluoral Yellow-088 (F); Nadi reagent (G); FeCl3 (H).

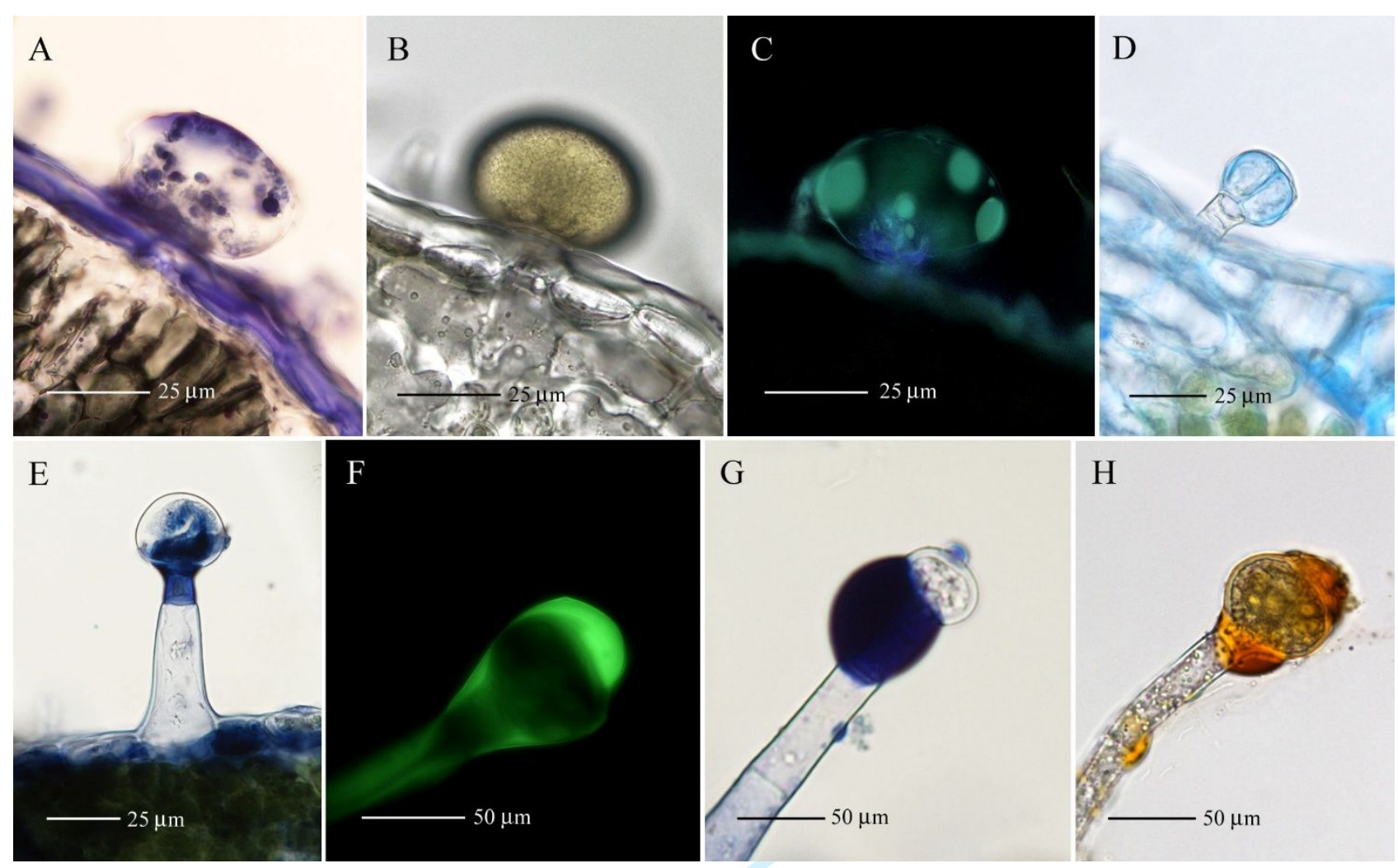

